\title{
VI \\ JUDICIALIZAÇÃO DA ATENÇÃO A CRIANÇAS, ADOLESCENTES E SUAS FAMÍLIAS E A (DES)PROTEÇÃO INTEGRAL: UMA ANÁLISE NA PERSPECTIVA DO SERVIÇO SOCIAL*
}

Eunice T. Fávero ${ }^{1}$

\section{Introdução}

Para a reflexão sobre a judicialização da atenção a crianças, a adolescentes e às suas famílias na relação com a (des)proteção integral, e na articulação com o Serviço Social, vários caminhos e várias indagações nos motivam, entre as quais duas são centrais e interrelacionadas. Uma delas nos remete a pensar por que, mesmo frente aos avanços conquistados no âmbito dos direitos de crianças, adolescentes e de suas famílias, especialmente a partir do paradigma da proteção integral adotada pelo Estatuto da Criança e do Adolescente - ECA (Lei n. 8. 069/1990), referenciada na Convenção dos Direitos da Criança (CDC/1989) e na Constituição Federal (BRASIL, 1998), se fazem ainda presentes no trabalho profissional realizado em espaços do sistema de garantia de direitos, entre os quais aqueles do sistema de justiça e das áreas da assistência social e da saúde, ações e manifestações perpassadas pelo "menorismo" que regia os dois códigos de menores que antecederam o ECA.

A segunda indagação nos leva a pensar por que, mesmo com as tantas normativas legais e ético-profissionais construídas pelo Serviço Social nas últimas décadas, na perspectiva do exercício profissional na defesa intransigente de direitos humanos, sem preconceito e sem discriminação, continuam sendo produzidas e reproduzidas, particularmente no âmbito da Justiça da Infância e Juventude (JIJ) aqui destacada, ações que culpabilizam as famílias por incapacidade de proteção, por negligência com suas crianças, por "não aderência" a pro-

\footnotetext{
*DOI - 10.29388/978-65-86678-28-4-0-f.129-153

${ }^{1}$ Dra. em Serviço Social pela PUCSP. Coordenadora do Núcleo de Estudos e Pesquisas sobre Crianças e Adolescentes: ênfase no Sistema de Garantia de Direitos - NCASGD, do PPGSSO/PUCSP. Pesquisadora sobre Serviço Social na Área Sociojurídica.

${ }^{2}$ Ver Cardoso (2018) e Berberian (2015).
} 
gramas de apoio para os quais eventualmente são encaminhadas - ações estas, muitas vezes, com suporte na opinião técnica emitida por assistente social.

Estudos sobre a história do Serviço Social e sobre a legislação destinada à infância e à juventude e sobre o peso da tradição positivista e conservadora presente nessas trajetórias nos fornecem pistas para explicar essa realidade, assim como análises sobre famílias e (des)igualdade de direitos, no interior de uma sociedade marcada pela desigualdade social e pelo avanço recorrente do público sobre o privado com intuito de controle da população trabalhadora e sua subalternização ao poder das elites, podem nos ajudar em reflexões a respeito. Mas são questões que demandam investimentos em amplas e rigorosas pesquisas históricas, teóricas e empíricas, para dar conta de respostas qualificadas e consistentes. Por isso mesmo, não é possível esgotá-las aqui, mas, sim, tão somente tomá-las como pontos de partida, estabelecendo algumas aproximações a essa realidade, no interior de um projeto ampliado de pesquisa ${ }^{3}$, em fase inicial de execução.

Assim, neste texto pretende-se traçar alguns apontamentos históricos sobre a legislação relativa a crianças e adolescentes e sobre o trabalho de assistentes sociais na justiça da infância e da juventude e/ou em espaços que com ela estabelecem interfaces, com um olhar tanto nas primeiras décadas do século XX como nas décadas recentes, tendo como recorte a visão que aí foi sendo instituída e reproduzida sobre família(s) e (des)proteção social de crianças e adolescentes, com destaque à proteção integral.

\section{A legislação menorista para preservação da moral e dos bons costumes}

O primeiro código de menores brasileiro (Lei n. 17.943-A, 1927) vigorou por 52 anos e visava explicitamente disciplinar e controlar os menores ${ }^{4}$ "abandonados e delinquentes". Sua construção e instituição se insere no processo de ampliação da industrialização e da urbanização desordenada nas primeiras décadas do século XX, que expunham as marcas da questão social, no caso, por meio do que os segmentos que dominavam o poder econômico e político consideravam como vadiagem e abandono, não por acaso personificados

\footnotetext{
${ }^{3}$ Projeto de pesquisa "Infâncias, Juventudes, Famílias e Sistema de Garantia de Direitos após 30 anos do ECA: interinstitucionalidades, intersetorialidades, trabalho social e dinâmicas socioterritoriais" (NCA-SGD, 2019).

${ }^{4}$ Conforme denominação adotada pelo referido código.
} 
nos "menores" provenientes de famílias de trabalhadores pobres, migrantes e/ ou descendentes da população escravizada. O foco da "atenção" a essas crianças e adolescentes vai passar, então, pelo Judiciário, por meio da organização de uma justiça que buscou tutelá-los e discipliná-los em nome da preservação da "moral e dos bons costumes". Isto é, a letra da lei e sua aplicação miraram o controle da moral e dos costumes das famílias da classe trabalhadora, a partir da perspectiva ideológica da classe detentora dos meios de produção e de poder e sua representação nos meios políticos e jurídicos, de maneira a mantê-los subalternizados e dóceis aos seus ditames.

O "problema do menor" era visto como "problema social" e a atenção a ele dispensada pelo Estado era a correcional-repressiva:

[...] o menor era visto como ameaça social e o atendimento a ele dispensado pelo poder público tinha por fim corrigi-lo, regenerá-lo, reformá-lo pela reeducação, a fim de devolvê-lo ao convívio social desvestido de qualquer vestígio de periculosidade, cidadão ordeiro, respeitador da lei, da ordem, da moral e dos bons costumes. (GOMES da COSTA, 1990, apud FÁVERO, 2005, p. 33).

Em estudos sobre o primeiro código de menores, Arthur de Oliveira Costa (1975) destaca o pensamento do jurista Noé de Azevedo, um dos influenciadores da sua criação, o qual afirmava que o juiz deveria inspirar-se

em sentimentos de uma justiça esclarecida, que não enxerga só as causas imediatas do crime, pesquisando a intenção do autor; ele vai estudar os seus antecedentes, as taras dos antepassados, os vícios do ambiente em que foi criado o menor, a fim de ensaiar um tratamento capaz de o resgatar e reconduzir para o grêmio da gente honesta. (OLIVEIRA COSTA, 1975, apud FÁVERO, 2005, p. 51).

Nesse sentido, para que o juiz de menores tivesse elementos além dos jurídicos para determinar a correção e/ou repressão, o código de menores previu em seus artigos 150 e 151 auxílio do médico psiquiatra e do comissário de vigilância. Ao primeiro caberia: "Proceder a todos os exames médicos e observações dos menores levados a juízo, e aos que o juiz determinar; fazer às pessoas das famílias das menores visitas médicas necessárias para as investigações dos antecedentes hereditários e pessoais destes". O comissário de vigilância, por sua vez, deveria "[...] proceder a todas as investigações relativas aos menores, seus 
pais, tutores ou encarregados de sua guarda, e cumprir as instruções que lhes forem dadas pelo juiz [...]”. (Apud. FÁVERO, 2005, p. 52).

Na mesma direção, o Decreto-lei n. 6.026/1943, que insere alterações nesse primeiro código, dispõe em seu artigo 10 que "em todos os casos, o juiz estudaria $[. .$.$] a personalidade do menor, sobretudo em seu ambiente familiar e$ social, mandando proceder reservadamente às perícias e inquéritos necessários à individualização do tratamento e da educação"(ibid.).

Dessa maneira, essa legislação dispôs sobre a presença de profissional com atribuições de estudar o comportamento do "menor" com vistas a subsidiar a decisão judicial, por meio da realização de inquirições e perícias. Profissional, e também comissário de vigilância na condição de voluntário, aos quais foi atribuído poder por força da lei que, aliado ao poder advindo do saber inerente à área de conhecimento e/ou de experiência de "pessoas de bem" (no caso dos comissários), lhes asseguravam legitimidade para dar suporte para o Estado/Judiciário tutelar e controlar crianças e adolescentes que, segundo os padrões ditados pelos segmentos dominantes e a visão adultocêntrica, poderiam se constituir em ameaças à sociedade.

No período histórico do estabelecimento desse código e nas décadas seguintes - e com a participação do Serviço Social a partir da década de 1940 -,

[...] a ênfase das causas do "problema de menores" era centrada na família. A família era individualizada, moralizada, e a análise de suas condições de vida não era articulada ao contexto socioeconômico desigual e excludente em que se situava. Numa perspectiva a-histórica, com base em formulações normativistas e disciplinadoras, a legislação referente a menores refletia o direito apartado da realidade social, formalizando uma visão dos problemas centrados no menor e na família pobre e estabelecendo regras de controle e vigilância de comportamentos. (FÁVERO, 2005, p. 51)

\section{A contribuição do Serviço Social no controle e vigilância dos "menores"}

O Serviço Social, ao ser institucionalizado no Brasil a partir de 1936, passa a ser área profissional privilegiada no trabalho junto a menores e famílias no espaço do Judiciário e afins. Com influências de pressupostos positivistas, do doutrinarismo social da Igreja Católica e do metodologismo do Serviço Social de casos individuais de matriz norte-americana (na perspectiva psicossocial), 
a profissão, de acordo com análise de Barroco sobre o primeiro código de ética profissional (1948), vai subordinar suas ações "à intenção ético-moral dos seus agentes, entendida como uma decorrência natural da fé religiosa", numa concepção da ética que traduzia os "[...] dogmas cristãos e a moral conservadora" na prática cotidiana, na "dicotomia entre bem e mal", buscando aperfeiçoar a personalidade das pessoas atendidas para que mantivessem "atitude habitual de acordo com as leis e os bons costumes da comunidade" (BARROCO, 2001, p. 96).

Nessa perspectiva, o apelo ético e moral, conforme a autora, vai contribuir para ocultar os elementos fundantes da questão social e transformar a moral em moralismo:

A moral adquire um sentido negativo, isto é, deixa de objetivar-se como espaço de realização de escolhas vinculadas à liberdade, como possibilidade de mediação entre as esferas e dimensões da vida social, para tornar-se um instrumento de alienação, favorecedor da legitimação da sociabilidade burguesa reificada. (BARROCO, 2001, p. 95)

Quando o Serviço Social foi requisitado para atuar no juizado de menores, em São Paulo (décadas de 1940/1950), essas influências, aliadas ao poder legal/institucional de inquirir, prescrever e determinar o comportamento do outro, passaram a dar o tom ao trabalho profissional. Se reportarmos aos discursos do meio profissional no período, registrados por pioneiras do Serviço Social e em trabalhos de conclusão de curso da Escola de Serviço Social, encontraremos bases de análise da realidade centradas na condição de vida e na moral familiar, estritamente articuladas aos princípios conservadores que norteavam o Serviço Social, entre os quais se evidenciava o doutrinaríssimo religioso de matriz católica.

Neves (1990), em sua tese de doutorado com base na história de Nadir Kfouri, uma das pioneiras do Serviço Social no Brasil, registra que, para o Serviço Social,

[...] a família deveria ser considerada tão essencial quanto a dignidade da pessoa humana, entendendo que essa instituição seria o espaço harmônico no qual o homem descobre suas potencialidades humanas desde que enunciadas como colaboradora do sagrado, e que a "sociedade deve ordenar-se ao serviço da família, a família ao serviço do homem e o homem ao serviço de Deus". (KFOURI , apud NEVES, 1990, p. 127-128). 
Trabalhos de conclusão de curso de Serviço Social analisados em pesquisa sobre a visão então predominante em relação a família, mulher e mãe ${ }^{5}$ revelam papéis esperados do homem e da mulher na vida familiar. À mulher caberia ser mãe, dedicada, amorosa e delicada. O homem, por sua vez, deveria ser rigoroso, viril e responsável pela autoridade familiar. Ambos deveriam ter clareza de sua missão e o matrimônio seria indissolúvel, e essa família idealizada seria imune às transformações sociais e culturais. Isto é, a família era a nuclear e patriarcal, com papéis bem definidos, cabendo ao homem as relações no espaço público e seu domínio, e à mulher os cuidados da vida familiar privada, ainda que, muitas vezes, tivesse que trabalhar fora do lar para prover despesas não supridas pelo homem, considerado seu "natural" provedor.

A visão sobre a mulher/mãe era assim traduzida: "Como ser mortal, é ela (a mulher/mãe) destinada à vida do lar, condensada nestas três palavras: filha, esposa e mãe. [...] O ambiente propício para a educação familiar e doméstica da moça é o próprio lar; a mestra por excelência é a mãe" (ROSSETTO, 1940, apud FÁVERO et al., 2010, s/p). A visão moralista em relação à mulher que "não cumpria" suas obrigações "naturais" se sobressaía, e por isso o trabalho da mulher fora do lar era visto como "desajuste". Ao mesmo tempo, considerava-se que nas famílias pobres a mãe era imprescindível, pois dela dependia toda a estrutura familiar. Todas as responsabilidades eram a ela transferidas, e quando o salário do marido não era suficiente para sustentar a casa, a mulher/mãe assumia mais uma responsabilidade: trabalhar ou buscar auxílio assistencial para colaborar com ele e garantir o provimento da família.

A partir dos anos de 1960, e especialmente nos anos de 1970, a tradição e o conservadorismo do Serviço Social começam a ser abalados com os ventos trazidos pelo Movimento de Reconceituação que percorreu vários países da América Latina, apontando para uma ruptura que se acentua na década de 1980 e se consolida no Brasil na década de 1990 com um novo projeto profissional. A ruptura com a direção conservadora estabelecerá entre seus princípios éticos indicativos do norte do trabalho profissional da/o assistente social a partir de então, na perspectiva da emancipação humana: a liberdade como valor ético central, a defesa intransigente dos direitos humanos, a defesa da democra-

5 Informações relatadas na pesquisa "Famílias: realidade social, política social e metodologia de trabalho - um estudo do trabalho do assistente social nas décadas de 1940 a 1970", desenvolvida sob orientação de FÁVERO, E., com participação de, MOURA, Maurice S. S., SANTANA, Neusa B. e SANTOS, Thaís, F. (em Iniciação Científica,). Ver o artigo das autoras: "Família, mulher e gênero - um estudo com base no trabalho do assistente social nas décadas de 1940 a 1970” - Anais CBAS, 2010. 
cia, a não discriminação e o não preconceito (de gênero/classe/etnia), e o compromisso com a qualidade dos serviços prestados (CFESS, 1993).

E será na mesma década da consolidação desse projeto, em sintonia com as lutas sociais que resultaram em conquistas de direitos com o fim da ditadura civil-militar, que a legislação e normativas sobre os direitos da infância e da juventude avançarão na perspectiva de que crianças e adolescentes são sujeitos de direitos, em condição peculiar de desenvolvimento, com prioridade absoluta e a quem deve ser assegurada a proteção integral.

Portanto, no interior do movimento social mais amplo que permeava a sociedade brasileira nesse período, na direção da superação da perspectiva conservadora e autoritária até então dominante, transformações na legislação profissional e na legislação infantojuvenil caminham ao mesmo tempo, estabelecendo bases e criando expectativas convergentes no sentido de que "um outro mundo", democrático e mais igual, seria possível. A retomada da democracia e a convergência de vários segmentos da sociedade em torno de propostas civilizatórias culminam na Constituição Federal de 1988 e, posteriormente, em leis infraconstitucionais, entre elas o Estatuto da Criança e do Adolescente - ECA.

\section{A doutrina da proteção integral e o sistema de garantia de di- reitos}

Em sintonia com diretrizes internacionais estabelecidas pela ONU na Convenção dos Direitos da Criança e com a Constituição Federal de 1988, o ECA incorporou a doutrina da proteção integral como paradigma nuclear. Com base nesse paradigma, a criança (entendida pela CDC como toda pessoa com menos de 18 anos de idade) é considerada em condição peculiar de desenvolvimento e deve ter assegurado tratamento como sujeito de direitos e com prioridade absoluta ${ }^{6}$.

A Convenção sobre os Direitos da Criança estabeleceu direitos específicos para crianças e adolescentes, relacionados à proteção - por exemplo, contra a violência e a exploração; à provisão - de educação, saúde, alimentação; à participação e à proteção específica - em relação a parte de população considerada vulnerável, como indígenas ou pessoa com deficiência. Como princípios, estabeleceu: a não discriminação, o seu melhor interesse, o direito à vida, à so -

\footnotetext{
${ }^{6}$ Algumas partes deste item remetem ao projeto de pesquisa referido na nota de rodapé n. 1 deste texto.
} 
brevivência e ao desenvolvimento, e o direito de opinar, serem ouvidos e levados a sério, considerando sua idade e maturidade.

Para a efetivação da proteção integral, foram pensadas a instituição e a articulação permanentes do Sistema de Garantia de Direitos da Criança e do Adolescente (SGDCA), que, em razão da incompletude institucional, pressupõe interinstitucionalidade na efetivação de uma política pública, intersetorial, base para a promoção, a defesa e o controle social de direitos infantojuvenis. A ideia do Sistema de Garantia de Direitos (como sistema estratégico) e de seus eixos nucleares de promoção, defesa e controle de direitos infantojuvenis contou com a fundamental participação de Wanderlino Nogueira Neto, um dos idealizadores do ECA:

De nada adianta colocar-se a luta pelo reconhecimento de direitos humanos de crianças e adolescentes, o reconhecimento de que são "sujeitos de direitos" e ao mesmo tempo "pessoas em condição peculiar de desenvolvimento", se com isso não se procurar garantir esses direitos, isto é, promovê-los e protegê-los por meio de instrumentos normativos (leis, tratados, resoluções, decretos etc.), de instâncias públicas (órgãos estaduais e entidades sociais, por exemplo) e de mecanismos (processos de mobilização, de construção de capacidades, de apoio técnico-financeiro, de monitoramento, de ações judiciais, do gerenciamento de dados e informações, de fundos de investimento etc.), todos com o mesmo fito. É preciso que se institucionalize e fortaleça um "sistema de garantia de direitos da criança e do adolescente" no país, nos moldes dos sistemas internacional e interamericano de promoção e proteção dos direitos humanos, aos quais o sistema nacional se articule e se integre. (NETO, 2005, p. 14)

Com esse sentido, o Conselho Nacional de Direitos da Criança e do Adolescente (CONANDA) estabeleceu as resoluções 113/abr. 2006 e 117/jul. 2006, que dispõem sobre a institucionalização e o fortalecimento do Sistema de Garantia de Direitos da Criança e do Adolescente, com base na interinstitucionalidade entre os poderes, particularmente o Judiciário e o Executivo.

\footnotetext{
7 "Art. $1^{\circ}$ O Sistema de Garantia dos Direitos da Criança e do Adolescente constitui-se na articulação e integração das instâncias públicas governamentais e da sociedade civil, na aplicação de instrumentos normativos e no funcionamento dos mecanismos de PROMOÇÃO, DEFESA E CONTROLE para a efetivação dos direitos humanos da criança e do adolescente, nos níveis Federal, Estadual, Distrital e Municipal" (CONANDA, 2006).
} 
A doutrina da proteção integral pressupõe a efetivação dos direitos, e a excepcionalidade da judicialização do atendimento:

Um dos principais diferenciais entre a atual "Doutrina da Proteção Integral à Criança e ao Adolescente" e a revogada "Doutrina da Situação Irregular" [pressuposto dos Códigos de Menores anteriores], aliás, é justamente a preocupação daquela com a "desjudicialização" do atendimento à criança e ao adolescente, pois na forma da Lei n ${ }^{\circ} 8.069 / 90$ a intervenção da autoridade judiciária, a rigor, deveria ocorrer apenas em casos excepcionais, quando fosse negado o atendimento por parte do Poder Público ou quando a própria lei estabelecesse tal exigência de maneira expressa. (DIGIÁCOMO, 2014, s/p) (grifo do autor).

O ECA, ao ter como fundamento a doutrina da proteção integral, deixa clara a necessidade da integralidade no atendimento aos direitos e necessidades da população infantojuvenil. Como afirma Tejadas (2009), isso exige incorporar a perspectiva democrática na condução das ações, com a divisão de poder, exigindo:

[...] um novo tipo de atuação do Estado, no qual as políticas públicas es tejam articuladas entre si, superando a histórica fragmentação presente nas ações estatais no Brasil. A gestão pública, assim, deve primar pela interlocução ativa e propositiva de todos os seus segmentos, que resulte em políticas intersetoriais e inter-relacionadas, possibilitando, dessa forma, a promoção de uma atenção integral. (TEJADAS, 2009, p. 46)

A aplicação e a materialização qualificadas dos princípios, diretrizes e direitos dispostos nas normativas legais dependem essencialmente da prioridade de investimentos por parte do poder público e do controle social democrático sobre suas ações e/ou sobre sua inércia. A materialização vai se dar lá na ponta, com a implementação e a execução dos serviços por meio dos quais crianças, adolescentes, jovens e suas famílias acessam o concreto dos direitos à educação, à saúde, à moradia, à cultura, ao lazer. E também a serviços decorrentes de demais políticas, entre elas a política de assistência social, com vistas a, entre outros aspectos, assegurar a convivência familiar e comunitária sempre que crianças e adolescentes tenham direitos violados ou em vias de o serem. 


\section{A judicialização da atenção e a participação do Serviço Social}

$\mathrm{Na}$ atualidade, após três décadas da promulgação do ECA e suas diretrizes de proteção integral (1990), e mais de quatro décadas da marca central da ruptura do Serviço Social brasileiro com o conservadorismo - em 1979, com o Congresso da Virada -, constata-se que a judicialização do atendimento de crianças e adolescentes tem se intensificado, em detrimento da efetivação do SGDCA, expressando-se basicamente com duas direções: por institucionalizações de crianças e adolescentes, responsabilizações e punições de adolescentes, jovens e famílias; e também pela busca individual do acesso a direitos fundamentais, quando negados ou não assegurados pelo Estado.

Nesses processos de judicialização, grande parte das vezes o trabalho de assistente social é requisitado para contribuir com a decisão judicial. E aqui a/o profissional, se não tiver segurança e domínio de suas competências técnicas e éticas, pode se ver enredada/o nas malhas da finalidade institucional de estabelecer o controle social e a punição para quem viola, ou é acusado de violar, o estabelecido pela positividade da lei, ou pela interpretação valorativa da lei com sua representação de classe social, para além da finalidade de assegurar direitos sociais e fundamentais dispostos constitucionalmente.

Ao ser requisitada/o para dar suporte à decisão judicial, muitas vezes por meio de prova pericial, a/o profissional corre o risco de ser alijada/o ou de se alijar dos deveres éticos e da direção social comprometida com a defesa intransigente dos direitos humanos, e (re)produzir opiniões técnicas na perspectiva conservadora, para além até da base original da profissão. Isso porque, se nas primeiras décadas do Serviço Social no Brasil o conservadorismo, a alienação e o preconceito podem ser explicados pela condição de classe social dos seus primeiros profissionais e pela consciência possível ${ }^{8}$ à época, na atualidade essa perspectiva seria, em tese, superada, na medida em que o Serviço Social avançou significativamente na produção de conhecimentos e na definição de um projeto profissional hegemônico que rompeu com a tradição conservadora e tem a perspectiva histórico-crítica a iluminar o conhecimento e a análise da realidade. Portanto, profissionais do Serviço Social na atualidade, na sua maior parte originários da classe trabalhadora, foram formados, ou deveriam ter sido formados, numa base curricular alicerçada pelos fundamentos e princípios desse projeto e em um período histórico democrático. Se há aqueles que não os in-

${ }^{8}$ A consciência possível “[...] se refere ao máximo de possibilidade histórica que a consciência de um grupo possa ter em um determinado momento" (GOLDMANN, apud BAPTISTA, 1986, p. 63). 
corporam no exercício profissional, produzindo ou reproduzindo preconceitos, discriminações e autoritarismos, necessário indagarmos: não tiveram acesso a uma formação qualificada (no interior do processo de mercantilização e precarização do ensino na atualidade), ou assumem conscientemente atitudes conservadoras e moralistas na relação com os usuários visando recuperar valores centrados na "moral e nos bons costumes"?

$\mathrm{Na}$ atualidade, é sabido que os sujeitos que figuram como "partes" nos processos da Vara da Infância e da Juventude (VIJ) têm, majoritariamente, trajetórias marcadas pela desigualdade social e pela negação de direitos fundamentais. A presença e a responsabilização da mulher/mãe, que vive em situação de pobreza, continuam aparecendo com certa regularidade em autos processuais de destituição do poder familiar, de acolhimento institucional, de adoção, entre outros $^{9}$. A opinião técnica de assistentes sociais nos processos da VIJ - registrada em relatórios, laudos e pareceres tanto do sistema de justiça como de organizações da rede socioassistencial que com ele mantém interfaces - pode e tem contribuído tanto para assegurar proteção como para embasar punições a esses sujeitos. Nesse sentido, é possível afirmar que "convivem" as perspectivas emancipatória e conservadora, com tendência ao conservadorismo e ao moralismo na definição do futuro de crianças e famílias, especialmente na interpretação da opinião técnica pelos operadores do Direito, visto que esta opinião, muitas vezes, é manifestada em relatos descritivos e breves, sem análise pertinente aos fundamentos teórico-metodológicos do Serviço Social. Isso é o que demonstram as pesquisas apontadas na nota de rodapé n. 9, revelando bases empíricas relativas a registros de manifestações técnicas e decisões judiciais nelas apoiadas, ou com enviesadas interpretações por parte daqueles a quem cabe a decisão.

Para adensar as reflexões e estabelecer algumas aproximações a possíveis respostas, vamos reportar algumas informações disseminadas sobre a realidade social e o acesso ou não aos direitos sociais por crianças, adolescentes, jovens e famílias na atualidade, que culminam na judicialização, para em seguida trazer um pouco do debate sobre particularidades do Serviço Social nessa realidade, em especial sobre a opinião técnica registrada em documentos que compõem autos processuais.

\footnotetext{
${ }^{9}$ Várias pesquisas têm revelado essa realidade. Entre elas, Fávero (2014), Berberian (2015) Cardoso (2018), Oliveira (2015).
} 


\section{Crianças, adolescentes e jovens no Brasil atual - marcas da realidade social}

Nas Varas da Infância e da Juventude, nas Varas da Violência Doméstica (VVD), nos Serviços de Acolhimento Institucional de Crianças e de Adolescentes (SAICAs), em serviços executados nos Centros de Referência Especializados de Assistência Social (CREAS) e nos Centros de Referência de Assistência Social (CRAS), em serviços que executam medidas socioeducativas destinadas a adolescentes em conflito com a lei (MSE), tem sido recorrente o atendimento de crianças, adolescentes, jovens, mulheres/mães, famílias que são encaminhadas, denunciadas, ou que os procuram em razão de alguma forma de desproteção de direitos, muitas vezes expressa em situações de violência, ruptura de vínculos familiares e sociais, desenraizamento territorial e social ${ }^{10}$, exclusão do trabalho, do direito à profissionalização, da saúde, da educação, da moradia, da cidade, na contramão da efetivação de princípios e diretrizes da doutrina da proteção integral que pressupõe, entre outros princípios, a desjudicialização do atendimento, conforme já observado neste texto ${ }^{11}$.

De acordo com o Relatório de Direitos da Criança no Brasil (Child Rights Now - CRN - Enfoque Social: 2019), desde 2015 têm avançado no Brasil os retrocessos com relação aos direitos sociais de crianças e adolescentes, em especial os direitos à educação de qualidade, à saúde, à convivência familiar; constatando-se também ampliação das desigualdades e aumento de número de crianças e adolescentes vivendo na pobreza, abusos e violências de gênero e intrafamiliar, e extermínio de adolescentes e jovens negros:

[...] são cerca de 33 milhões (61\% do total) vivendo na pobreza ou em situação de privação de direitos, 2,5 milhões fora da escola, cerca de 47 mil vivendo em serviços de acolhimento, mais de 9 mil vítimas de homicídio por arma de fogo, 109 mil meninas de 15 a 19 anos que se casaram em 2017 e mais de 100 mil meninas que se estima sofrerem violência sexual todos os anos. (CRN, 2019, p. 7-8)

O Atlas da Violência (IPEA/FBSP, 2019), por sua vez, revela que o índice de jovens ( 15 a 29 anos) vítimas de homicídio tem crescido no Brasil nos últimos 30 anos:

${ }^{10}$ Ver Gois (2014; 2018).

${ }^{11}$ Neste item também reportamos conteúdo do projeto de pesquisa indicado na nota de pé de página n. 1. 
Em 2017, 35.783 jovens foram assassinados no Brasil. Esse número representa uma taxa de 69,9 homicídios para cada 100 mil jovens no país, taxa recorde nos últimos dez anos. Homicídios foram a causa de 51,8\% dos óbitos de jovens de 15 a 19 anos; de 49,4\% para pessoas de 20 a 24; e de $38,6 \%$ das mortes de jovens de 25 a 29 anos; tal quadro faz dos homicídios a principal causa de mortes entre os jovens brasileiros em 2017 (tabela 1.1). (p. 25)

Os adolescentes que praticam ou que são acusados de participar de algum ato infracional vêm sendo cada vez mais colocados na berlinda e, em vez da ampliação de investimentos sociais para efetivação de direitos que cabem a esses "sujeitos de direitos", incluindo programas socioeducativos qualificados e com sua efetiva participação, a eles são direcionados projetos de lei visando a redução da maioridade penal, a ampliação da responsabilização e da punição e o encarceramento. Ainda que reiteradamente o apelo à redução da maioridade penal e o encarceramento sejam evocados para fazer frente à violência cuja autoria lhes é atribuída indiscriminadamente, os números sobre a realidade não sustentam essa narrativa. Tomando por base o levantamento do Sistema Nacional de Atendimento Socioeducativo - SINASE sobre atos infracionais de 2014, Azevedo e Terra (2018, p. 29) analisam que roubo, furto e atos contra o patrimônio são os mais praticados por adolescentes, refutando "[...] a noção do senso comum que alardeia um suposto aumento de crimes contra a pessoa (latrocínios e homicídios)". Nesse sentido, levantamento do Sistema Nacional de Atendimento Socioeducativo (SINASE/LEVANTAMENTO, 2016) traz indicativos reveladores: dos 26.868 adolescentes em cumprimento de medidas de internação e restritivas de liberdade, $46 \%$ (12.724) foram atos “'...] classificados como análogo a roubo e $24 \%$ (6.666) foram registrados como análogo ao tráfico de drogas. O ato infracional análogo ao homicídio foi registrado em 10\% (2.788)".

Em relação às disposições do ECA sobre medidas de proteção, têm se acentuado nos anos recentes as investidas na inversão de prioridades, ou seja, a priorização da colocação da criança em família substituta, especialmente mediante adoção, última das medidas previstas (num rol de nove), em detrimento do investimento na permanência da criança com a família de origem, mediante efetivação de políticas públicas de proteção social sempre que a separação tenha como base a ausência ou fragilidade de condições materiais para os cuidados. Nesse sentido, recorrentemente são apresentados projetos de lei no Congresso Nacional visando alterar o ECA e, em muitos casos, fragmentá-lo, num proces- 
so de desconfiguração do paradigma da proteção integral que sustenta sua proposta original. Vários desses projetos de lei (PL) focam especialmente na "agilização" da adoção de crianças e "agilização" da destituição do poder familiar como exemplo, o PLS sobre o Estatuto da Adoção (PLS n. 394/2017), que pretende colocar a adoção como política pública, e o PL sobre Adoção "intuitu personae" (PL n. 369/2016), voltado para a facilitação da "entrega direta" da criança pela família de origem à pessoa/família adotante, sem passar pelas normativas construídas para o devido processo social e legal da adoção, passíveis de controle social democrático.

Esses e outros PL têm como foco crianças, adolescentes e famílias pobres, alinham-se à retirada do Estado enquanto um dos principais responsáveis pela efetivação da proteção integral, e priorizam a adoção como política pública "salvacionista", em detrimento do investimento em políticas públicas que assegurem a proteção social e, com isso, o que seria o investimento na prioridade ao direito da criança e do adolescente à convivência com a família de origem, sempre que eventual perspectiva de separação se anuncie em razão das condições de pobreza e não por falta de afeto/desejo de cuidar.

Como principal justificativa dos projetos de lei voltados para a adoção como política pública e para a celeridade da destituição do poder familiar, geralmente citam-se dados do Conselho Nacional de Justiça (CNJ), tais como: a existência de 47.316 crianças e adolescentes acolhidos em instituições; destes, 5.021 "disponíveis" para adoção (isto é, cujos pai/mãe foram destituídos do poder familiar). Por outro lado, o número de pretendentes à adoção cadastrados soma $45.765(\mathrm{CNJ} / 2019,2019 \mathrm{a})$.

Entretanto, dados disponibilizados pelo próprio CNJ (CNJ/2019, 2019a), relativos às indicações feitas pelos 45.765 pretendentes à adoção sobre raça/etnia, grupo de irmãos e condições de saúde, e dados sobre essas características em relação às 5.021 crianças cadastradas, que poderiam ser adotadas, revelam total desencontro de necessidades e de interesses, ou entre a criança idealizada e a criança real. Isto é, a maior parte dos pretendentes à adoção deseja crianças brancas, com até 3 anos de idade, sem irmãos e sem problemas de saúde. Por outro lado, as crianças em condições de serem adotadas (isto é, que pas saram por todo o trâmite legal e poderiam ser inseridas em famílias substitutas) são em maioria negras, grupos de irmãos, significativa parcela com algum problema de saúde e com mais de 10 anos de idade (CNJ, 2019, 2019a).

Pesquisa sobre a perda do poder familiar em autos processuais no Judiciário de São Paulo (FÁVERO, 2014, 2014a) revela uma realidade em que as mulheres/mães e alguns pais que são destituídos do poder familiar (e cujos fi- 
lhos vão para a adoção ou, em sua maior parte, permanecem institucionalizados até a maioridade), em sua maioria não têm qualquer perspectiva de vida digna, estão sem vínculos de proteção (social e familiar), são totalmente invisíveis para a sociedade. Aí aparece explicitamente que, na perda do poder familiar, gênero e classe social ${ }^{12}$ são centrais: quem perde o poder familiar, na maioria das vezes, é a mulher/mãe, pobre ou abaixo da linha de pobreza, sem acesso a direitos sociais nem antes nem após a perda do poder familiar (FÁVERO, 2014).

Produz, permeia e sustenta essa caótica e violenta realidade a histórica e acentuada desigualdade estrutural existente no país. Grande parte da população, formada por trabalhadores (com ou sem vínculos trabalhistas, inseridos ou não no trabalho formal ou mesmo informal), vive em situação de pobreza, sem acesso a recursos para uma vida digna. Relatório da Oxfam analisando dados do IBGE aponta que, no Brasil, "os rendimentos mensais médios do 1\% mais rico representam 36,3 vezes mais que aqueles dos $50 \%$ mais pobres. Considerando os dados das declarações de IRPF, tal razão seria de 72 vezes" (OXFAM, 2018, p. 18). O relatório aponta ainda o aumento da desigualdade de renda entre grupos étnicos, assim como entre homens e mulheres. Ao mesmo tempo, reduzem-se os gastos sociais nos últimos anos (basicamente em previdência, assistência social, saúde e educação), no interior de um projeto de diminuição do Estado para os pobres: esses gastos que "já significavam, em 2016, a redução de 13 pontos percentuais em relação ao espaço fiscal ocupado pelos gastos sociais de anos anteriores, num retorno repentino para níveis de 2001. Trata-se de um retorno de 17 anos de priorização de investimentos sociais contra desigualdades" $^{\prime 13}$ (ibid., p. 45).

O mesmo relatório conclui que

[...] as pessoas pobres no Brasil - aqui considerando os $40 \%$ mais pobres cuja renda individual média é de $\mathrm{R} \$ 696,20$ - dependem fortemente do Estado para incrementar suas rendas, bem como para acessar postos de saúde, hospitais, clínicas, postos de vacinação, creches e escolas de educação fundamental. Medidas que limitam a capacidade do Estado de realizar políticas voltadas para esses serviços, que representam direitos constitucionais, têm brutal impacto nas rendas familiares, reduzindo-as, e aumentando a pobreza e as desigualdades. (OXFAM, 2018, p. 50)

\footnotetext{
12 Ainda que por meio de fotos de documentos inseridos nos processos seja possível inferir que raça/etnia centrada na população negra também seja predominante, as informações processuais pesquisadas geralmente não registram esse indicador.

13 A Emenda Constitucional n. 95/2016 instituiu Novo Regime Fiscal, por meio do qual os gastos federais são congelados com base em valores de 2016.
} 
No interior dessa multifacetada e bárbara realidade, nos anos recentes têm sido ampliados os discursos e ações governamentais, assim como de alguns segmentos religiosos, notadamente ligados a movimentos e/ou igrejas neopentecostais ultraconservadores com discurso "salvacionista-religioso" ${ }^{14}$, na direção de retroceder em avanços civilizatórios conquistados especialmente a partir da Constituição Federal de 1988 no que se refere aos direitos fundamentais e sociais, e investir nos chamados valores da "família tradicional". Isto é, aqui o discurso com foco na moral e nos bons costumes dá o tom, com alguma similaridade àquele proferido nas primeiras décadas do século XX, que marcava a posição dos que defendiam o controle do "menor abandonado e delinquente" e de sua família, no interior dos valores conservadores. Na atualidade, cada vez mais são presentes em espaços públicos acontecimentos e posicionamentos conservadores, com teores preconceituosos, permeados por expressões de violências em relação ao que se entende por diversidade de família(s) e relações familiares. Essas posições repercutem em espaços socioocupacionais do Serviço Social e de outras áreas das ciências humanas, sociais e da saúde, e, com relativa frequência, a judicialização das relações sociofamiliares tem sido acionada para fazer coro a elas e à ausência e/ou à ineficiência de políticas públicas, assim como à incapacidade ou dificuldade de indivíduos, grupos e/ou instituições de lidar com o diferente, com o direito de escolha da/o outra/o em relação à sua vida privada, ou com a impossibilidade de escolha, ditada pela barbárie social que direciona suas vidas.

Diante desse quadro social aqui brevemente exposto, importam também algumas reflexões sobre como o Serviço Social, em particular no espaço do Judiciário, tem contribuído, ou pode vir a contribuir, para desvelar a realidade de crianças, adolescentes e suas famílias, levando em conta situação de classe social, gênero e raça/etnia, com vistas a um trabalho alinhado a uma direção so cial comprometida com a promoção, a proteção e a defesa de seus direitos, e em articulação com a rede socioassistencial. Ou, se na contramão dessa direção, contribui com análises numa perspectiva moralizante, com atuações isoladas e individualizadas, dando suporte a responsabilizações e punições, no interior de uma perspectiva conservadora da "moral e dos bons costumes". Enfim, refletirmos um pouco sobre quais os valores e perspectivas conceituais e técnicas dire-

\footnotetext{
${ }^{14}$ Ver Burnatelli e Lahuerta (2014): O neopentecostalismo e os dilemas da modernidade periférica sob o signo do novo desenvolvimentismo brasileiro.
} 
cionam esse trabalho, particularmente com crianças, adolescentes e suas famílias.

\section{O Serviço Social na Justiça da Infância e da Juventude e a perspectiva de análise da(s) família(s)}

Diante do projeto profissional que tem base na ruptura com o conservadorismo e com o moralismo no exercício do trabalho, como as/os assistentes sociais têm atuado nos serviços que compõem (ou deveriam compor) o Sistema de Garantia de Direitos? Como têm se manifestado frente a situações de desproteção social com potencial fragilização e/ou ruptura de vínculos da criança com sua família? Qual a base teórica e ética da "opinião técnica" que emitem sobre as expressões da questão social que se apresentam no cotidiano de trabalho? As expressões cada vez mais frequentes e ampliadas do conservadorismo e moralismo por parte de grupos sociais, políticos e religiosos tem rebatido no trabalho profissional, especialmente no espaço do Judiciário, historicamente e "naturalmente" alinhado à manutenção da ordem burguesa capitalista?

Barroco (2015), em debate sobre a ofensiva neoconservadora na atualidade e lembrando que o conservadorismo percorre toda a trajetória profissional de assistentes sociais, observa que

[...] o interesse maior, oculto no assédio moral exercido sobre a profissão para que ela execute tarefas contrárias ao Código de Ética Profissional e às suas atribuições legais, é o de que ela seja coadjuvante desse moralismo punitivo no enfrentamento das expressões da questão social, como já foi em outros tempos; que mais uma vez o Serviço Social se adeque a essa missão restauradora da lei e da ordem social. (BARROCO, 2015, p. 634)

Nesse debate, questionando se o conservadorismo está ou não sendo superado no processo de construção do projeto profissional direcionado à sua ruptura, Barroco nos lembra que a profissão "reflete as contradições sociais, suas tendências e, como tal, a luta pela hegemonia entre ideias e projetos profissionais e societários" (ibid.)

Nos limites do possível neste texto, e entendendo que se faz necessário investir em mais pesquisas para dar conta da amplitude das respostas necessárias a essas indagações, trazemos alguns apontamentos relacionados aos funda- 
mentos e à operacionalização da opinião técnica que assistentes sociais emitem em informes, relatórios e laudos que compõem prontuários em serviços e autos processuais no Judiciário.

No espaço de trabalho da Justiça da Infância e da Juventude, que se insere na área sociojurídica, e naqueles da rede socioassistencial com os quais estabelecem interfaces na execução das medidas protetivas e socioeducativas, assistentes sociais são requisitadas/os a contribuir, entre outros aspectos, com a "constatação da verdade dos fatos", por meio de estudos sociais/perícias sociais e registros como informes, relatórios, laudos, pareceres etc. O processo (estudo social) e o produto do trabalho materializado por meio desses registros, geralmente, são vistos pelo Estado/Juízo da Infância e da Juventude como capazes de conter/constatar a "verdade" sobre a situação em análise ou julgamento. Portanto, como provas periciais para base à acusação (pelo Ministério Público) e à decisão (pelo juiz).

Frente a essa expectativa, importa compreender qual é a concepção de verdade no sentido jurídico. Marcondes (2014, p. 48) explica que, nessa esfera, a verdade identifica-se com justiça: "o estabelecimento da verdade dos fatos para absolver ou condenar um réu". Todavia, na perspectiva epistemológica, a verdade está relacionada ao conhecimento da realidade - que se articula ao conhecimento científico (ibid.).

Como ensina Chauí (2002), a ciência "desconfia" dos fatos, desconfia do que se coloca no imediato, o que implica a busca do conhecimento da realidade na perspectiva crítica, investigando os diversos fatores que levaram ao "fato concreto" que, no caso do Serviço Social, remete à expressão da questão social que chega às/aos profissionais enquanto demanda a ser respondida no cotidiano de trabalho. Nessa perspectiva, a expressão da questão social na sua imediaticidade será o ponto de partida de um caminho de análise que passa pela sua desconstrução por meio da localização das particularidades que a conformam; um ponto de partida a ser cercado de indagações que possibilitem estabelecer a relação entre sua singularidade e sua universalidade. Assim, se a acusação de negligência de uma mulher/mãe chega como expressão imediata da questão social, cabe questionar: o que é negligência? Qual o conceito que a sustenta? Qual a condição dessa mulher/mãe para cuidar, para assegurar proteção à criança? Qual acesso teve aos direitos fundamentais na atualidade e em seu percurso de vida? Qual o lugar em que se coloca ou é colocado o homem/pai nesse processo? A condição de raça/etnia, e o preconceito à qual pode estar sujeita, interfere de alguma maneira na situação vivenciada que culminou na judicialização? Qual a participação do Estado nesse processo, enquanto principal res- 
ponsável por assegurar a proteção social/proteção integral? Enfim, necessário se faz percorrer o caminho de volta, do imediato para os elementos sociais explicativos da condição que se apresenta. Nessa direção, o sentido e o caminho epistemológicos do conhecimento da realidade do "fato" pelo Serviço Social não são os mesmos do sentido jurídico.

Para o Direito positivo e a Justiça, o conceito de verdade é fundamental. Em um processo "se busca estabelecer a verdade dos fatos", o que permite "fazer valer direitos, condenar ou absolver". E aí, "as questões sobre 'o sentido de verdade' não podem permanecer em aberto". Por isso, "o sistema jurídico prescreve princípios e procedimentos sobre "como chegar à verdade" (MARCONDES, 2014, p. 47-53). Nesse sentido, busca-se a verdade enquanto correspondência com os fatos, o que requer saber o que "realmente se passou", para a tomada de decisão e/ou para fazer justiça (ibid.)

Mas, afinal, o que são os "fatos"? A lei os define como "os acontecimentos que motivam a ação judicial à luz do sistema legal" e de sua interpretação no interior da positividade da legislação. E aqui, isto é, na intepretação da lei, a visão de mundo, valores, crenças e opções políticas por parte de quem opera a lei se fazem presentes e podem ditar o tom da decisão sobre a vida do outro. Conforme explica Borgianni,

[...] o Direito Positivo, por possuir um caráter de classe, impõe a defesa dos interesses da classe dominante e, portanto, seja no acesso ao complexo aparelho de justiça burguês, e mesmo nos instrumentos de convencimento de seus operadores a lógica da defesa da classe dominante se faz presente. Tal fundamento possui relevância determinante na vida das pessoas, uma vez que ao serem "julgadas por algum crime, ou por algum ato ilícito, estarão, no limite, à mercê dessa discricionariedade de classe, ainda que isso se dê com muitas e complexas mediações" (BORGIANNI, 2012, apud CFESS, 2014, p. 50).

Mas o que a/o assistente social, e o processo de trabalho "estudo social" que desenvolve nos espaços do Judiciário ou em organizações demandadas a oferecer informações sobre a situação de crianças e famílias, tem a ver com isso? Saber do que "realmente se passou" para a tomada de decisão judicial requer, entre outras, a "prova pericial" que, no caso do Serviço Social, se traduz na perícia social - que entendemos seguir a mesma operacionalidade e fundamentação do estudo social em Serviço Social. Prova que não necessariamente segue o rigor que se espera da realização de uma perícia, ou para a qual não se 
exige e não se asseguram condições de trabalho para garantir esse rigor. Isto é, um breve informe, um relato essencialmente descritivo, podem ser vistos por operadores do Direito como "prova pericial" para sustentar uma decisão judicial, em especial quando estão envolvidas pessoas e famílias que não têm acesso a uma rigorosa e competente defesa jurídica.

Sabemos que em tempos de avanço da judicialização das relações e das expressões da questão social, o estudo social pode ser requisitado ou proposto com vistas a subsidiar acesso e assegurar direitos - o que pressupõe atuação com competência teórica, metodológica e técnica, em sintonia com os princípios éticos que alicerçam o projeto profissional hegemônico do Serviço Social. No entanto, contraditoriamente a esse projeto que tem como um de seus princípios basilares a defesa intransigente de direitos humanos, o estudo social pode ser requisitado para oferecer subsídios que contribuam com a revelação da "verdade dos fatos" e, assim, figurar como a ou uma das "provas" para punições a potenciais violadores, ou acusados de violação de direitos, ainda que a intencionalidade profissional não se coloque com essa perspectiva. Em situações como essas, pode vir a dar respaldo, portanto, a requisições conservadoras de controle e de disciplinamento na perspectiva moralizante da vida privada da população, a serviço da ordem capitalista burguesa, tal como as que alicerçaram suas bases práticas originalmente.

As requisições da área sociojurídica estimulam a "abordagem individual", o que é predominante na Justiça da Infância e da Juventude. Nesse sentido, os estudos "individuais", quando não desenvolvidos com competência técnica e ética que considere a perspectiva de totalidade, podem dar margem à redução da abordagem, limitando o estabelecimento das mediações da relação singular/universal, favorecendo expressões moralizantes e conservadoras sobre as famílias, nos pareceres emitidos. O discurso expresso por vezes na intenção "salvacionista", justificado pelo "melhor interesse da criança", pode favorecer o preconceito e a banalização da condição de vida das famílias, de sua condição ou não de acesso aos direitos fundamentais, dispostos constitucionalmente, para assegurar cuidados e proteção às crianças.

Desconstruir o imediato posto no trabalho cotidiano exige fazer perguntas à realidade. O "que" se busca conhecer, afinal? O sujeito e sua capacidade "individual", alheias às determinações sociais? A "família", suas relações e formas de constituição? Mas a partir de quais referenciais? De modelos "idealizados" ou respeitando diversidades e escolhas das pessoas sobre como e com quem se relacionar? A relação entre estrutura/conjuntura e seu rebatimento na expressão da questão social que afeta a vida do(s) sujeito(s) tem sido desvelada? 
Percorrer esse caminho requer investimento permanente nas competências técnico, ética e política, para avanços no trabalho profissional que possam revelar a "trama das relações sociais", na perspectiva crítica; para não trans formar as manifestações da questão social em "problemas de violência", que tendem a culpabilizar ou criminalizar sujeitos ou grupos subalternos, conforme nos ensina Ianni (2004); para não compactuar com o avanço do conservadorismo na "tutela do Estado sobre a intimidade"; para não respaldar avaliações que atribuam imoralidades a pessoas/famílias que não correspondam a modelos preconizados pelas forças conservadoras que avançam em relação ao encolhimento do espaço público e alargamento do controle do espaço privado (MAN DELBAUM; SARAIVA, 2017, p. 153-170).

No tempo presente, 30 anos da promulgação do ECA e 40 anos da "virada" do Serviço Social, uma chave fundamental dos estudos sociais e de demais requisições de trabalho exige priorizar o conhecimento e a análise da realidade de crianças, adolescentes e famílias, tomando por base o acesso ou não aos direitos constitucionalmente estabelecidos e legislados no ECA: educação é direito fundamental; saúde, alimentação e meio ambiente são direitos fundamentais; moradia e acesso à cidade são direitos fundamentais; convivência familiar e comunitária é direito fundamental; esporte, arte e cultura são direitos fundamentais ${ }^{15}$.

Antes de cobrar das famílias proteções e cuidados para com os seus, necessário se faz saber a quais direitos os sujeitos tiveram acesso, com o quê e com quem contaram e contam, efetivamente, para a vida com dignidade. Essa é uma exigência fundamental para contribuir com ações concretas frente ao avanço conservador que ignora ou escamoteia a realidade social extremamente desigual desde sempre presente no Brasil, que continua banalizando, perpetuando e incentivando a violência material e simbólica contra a população trabalhadora expressa por diversas formas, entre elas pelo avanço da judicialização, da responsabilização, do punitivismo, do descarte daqueles que não servem ao mercado e ao consumo.

\footnotetext{
${ }^{15}$ Essas são as chamadas da Campanha Proteger é Garantir Direitos, promovida pelo Movimento pela Proteção Integral de Crianças e Adolescentes durante o ano comemorativo dos 30 anos doo ECA. Ver:

<https://pt-br.facebook.com/MovimentoProtecaoIntegralCriancasAdolescentes/>.
} 


\section{Referências}

AZEVEDO, F.; TERRA, C. Adolescente, ato infracional e Serviço Social no Judiciário: trabalho e resistências. São Paulo: Cortez, 2018.

BAPTISTA, M. V. Goldmann e o estruturalismo genético. Serviço Social e Sociedade, São Paulo, n. 21, p. 55-65, 1986.

BARROCO, M. L. Ética e Serviço Social: fundamentos ontológicos. São Paulo: Cortez, 2001.

. Não passarão! Ofensiva neoconservadora e Serviço Social. Revista

Serviço Social e Sociedade, São Paulo, n. 124, p. 623-636, 2015.

BERBERIAN, T. P. Serviço Social e avaliações de negligência: debates no campo da ética profissional. Revista Serviço Social e Sociedade, São Paulo, n. 121, p. 48-65, 2015.

BRASIL. Decreto n. 99.710, de 1990. Promulga a Convenção sobre os Direitos da Criança. Lex: . Disponível em: < http://www.planalto.gov.br/ccivil 03/decreto/1990-1994/d99710.htm>. Acesso em: 10 jul. 2019.

. Constituição da República Federativa de 1988. Disponível em:

$<$ http://www.planalto.gov.br/ccivil_03/constituicao/constituicao.htm $>$. Acesso em: 28. Jun. 2019.

BURNATELLI, G. H.; LAHUERTA, M. O neopentecostalismo e os dilemas da modernidade periférica sob o signo do novo desenvolvimentismo brasileiro. Revista Brasileira de Ciência Política, Brasília, n. 14, p. 57-82, 2014. Disponível em: < http://www.scielo.br/pdf/rbcpol/n14/0103-3352-rbcpol-1400057.pdf>. Acesso em: 15 nov. 2019.

CARDOSO, G. F. de L. Trabalho social com famílias em tempos de judicialização e criminalização da pobreza: do discurso da "não aderência" ao direito a proteção. Caderno da Defensoria Pública do Estado de São Paulo, São Paulo, v. 3, n. 19, p. 58-73, out. 2018. Disponível em: < https://www.defensoria.sp.def.br/cadernos defensoria/volume19.aspx >. Acesso em: 25 mar. 2019. CFESS. Resolução CFESS n. 273/1993. Código de Ética Profissional do/a assistente social. Brasília: CFESS, 1993. Disponível em: < http://www.cfess.org.br/arquivos/CEP CFESS-SITE.pdf>. Acesso em: 10 nov. 2019.

Atuação de assistentes sociais no sociojurídico: subsídios para reflexão. Brasília: CFESS, 2014. Disponível em: < $\underline{\text { http://www.cfess.org.br/js/li- }}$ 
brary/pdfjs/web/viewer.html?pdf=/arquivos/CFESSsubsidios sociojuridico2014.pdf>. Acesso em: 10 mar. 2019.

CHAUÍ, M. Convite à Filosofia. 6. ed. São Paulo: Ática, 2002.

CNJ. Cadastro Nacional de Adoção. Brasília: CNJ, 2019. Disponível em:

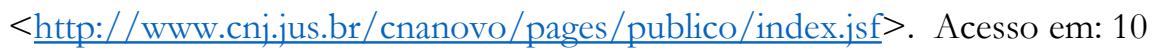
ago. 2019.

. Relatório de Crianças Cadastradas. Brasília: CNJ, 2019a. Disponível em: $<$ http://www.cnj.jus.br/cnanovo/pages/publico/index.jsf $>$. Acesso em: 10 mar. 2019.

CONANDA. Resolução n. 113, de 19 de abril de 2006. Dispõe sobre os parâmetros para a institucionalização e fortalecimento do Sistema de Garantia dos Direitos da Criança e do Adolescente. Disponível em: < $\underline{\text { http:/ / www.direitosda- }}$ crianca.gov.br/conanda/resolucoes/113-resolucao-113-de-19-de-abrilde2006/view >. Acesso em: 26 jun. 2019

. Resolução n. 117, de 11 de julho de 2006. Altera dispositivos da Resolução n. 113/2006, que dispõe sobre os parâmetros para a institucionalização e fortalecimento do Sistema de Garantia dos Direitos da Criança e do Adolescente. Disponível em: < http://www.direitosdacrianca.gov.br/conanda/resolucoes/117-resolucao-117-de-11-de-julhode-2006/view >. Acesso em: 1 jul. 2019. CRN. Child Rights Now. Relatório de Progresso dos Direitos da Criança no Brasil. Enfoque Social, Brasil, 2019. Disponível em: < https:/ www.migalhas.com.br/arquivos/2019/7/art20190710-09.pdf>. Acesso em: 14 jul. 2019. DIGIÁCOMO, M. O Sistema de Garantia de Direitos da Criança e do Adolescente. 2014. Disponível em: < http://www.crianca.mppr.mp.br/modules/conteudo/conteudo.php? conteudo=1590>. Acesso em: 9 jul. 2019.

FÁVERO, E. Serviço Social, práticas judiciárias, poder: implantação e implementação do Serviço Social no Juizado da Infância e Juventude de São Paulo. 2. ed. São Paulo: Veras, 2005.

\section{. (Coord.). Relatório Pesquisa Realidade Social, Direitos e Perda}

do Poder Familiar: desproteção social x direito à convivência familiar e comunitária. Relatório Final. São Paulo: Unicsul, março de 2014. Digitalizado.

. Barbárie social e exercício profissional: apontamentos com base na realidade de mães e pais destituídos do poder familiar. In: FÁVERO, E.; GOES, D. Serviço Social e temas sociojurídicos: debates e experiências. Rio de Janeiro: Lúmen Juris, 2014a. 
FÁVERO, E.; MOURA, M. S.; SANTANA, N. B.; SANTOS, T.; F. Família, mulher e gênero: Um estudo com base no trabalho do assistente social nas décadas de 1940 a 1970. In: Anais do XIII CBAS: CFESS/ABEPSS, 2010. CDROM.

GOIS, D. A. Famílias, desenraizamento social e privação de direitos. In: FÁVERO, E.; GOIS, D. A. Serviço Social e Temas Sociojurídicos. Rio de Janeiro: Lumen Juris, 2014.

. Famílias e Trabalho Social: Eixos Norteadores. In: GOIS, D. A. Fa-

mília e Trabalho Social: trilhando caminhos no Serviço Social. São Paulo: Papel Social, 2018.

IANNI, O. A ideia de Brasil moderno. São Paulo: Brasiliense, 2004.

IPEA/FBSP. Atlas da Violência 2019. Brasília/Rio de Janeiro: IPEA/FBSP, 2019.

. Decreto Lei N. 17.943 de 1927. Código de Menores (Código Melo

Matos). Disponível em: <https://www2.camara.leg.br/legin/fed/decret/19201929/decreto-17943-a-12-outubro-1927-501820-publicacaooriginal-1-pe.html.> Acesso em: 03 de nov. 2020.

BRASIL. Lei no 8.060/1990. Estatuto da Criança e do Adolescente. Disponível em: <http://www.planalto.gov.br/ccivil 03/leis/18069.htm >. Acesso em: 1 abr. 2019.

. PLS 394 de 2017. Disponível em: < $\underline{\text { https://www25.senado.leg.br/ }}$ web/atividade/materias/-/materia/131275 >. Acesso em: 04 dez. 2019.

. PL 369 de 2016. Disponível em: < https://www25.senado.leg.br/ web/atividade/materias/-/materia/127082>. Acesso em: 04 dez. 2019.

MANDELBAUM, B.; SARAIVA, L. F. O. A farsa da destruição da família em tempos de conservadorismo. In: - (Org.) Família, contemporaneidade e conservadorismo. São Paulo: Benjamin Editorial, 2017.

MARCONDES, D. A verdade. São Paulo: WMF Martins Fontes, 2014.

MOURA, Maurice S. S., SANTANA, Neusa B. e SANTOS, Thaís, F. "Família, mulher e gênero - um estudo com base no trabalho do assistente social nas décadas de 1940 a 1970”. CFESS/ABEPSS, 2010. CD-ROM.

NCA-SGD. Projeto de pesquisa "Infâncias, Juventudes, Famílias e Sistema de Garantia de Direitos após 30 anos do ECA: interinstitucionalidades, intersetorialidades, trabalho social e dinâmicas socioterritoriais”. NCA-SGD/PUCSP, 2019. Digitalizado. 
NEVES, N. P. Nadir Gouvêa Kfouri: o saber e a prática do Serviço Social no Brasil. 1990. Tese (Doutorado em Serviço Social) - Programa de Estudos PósGraduados em Serviço Social. Pontifícia Universidade Católica de São Paulo, São Paulo, 1990.

NETO, W. N. Por um sistema de promoção e proteção de direitos humanos de crianças e adolescentes. Revista Serviço Social e Sociedade, n. 83, p. 5-29, São Paulo: Cortez, 2005.

OLIVEIRA, R. C. No melhor interesse da criança? A ênfase na adoção como garantia à convivência familiar e comunitária. 2015. 234 fls . Tese (Doutorado em Serviço Social) - Programa de Estudos Pós-Graduados em Serviço Social, Pontifícia Universidade Católica de São Paulo, São Paulo, 2015. Dispo-

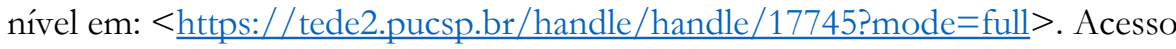
em: 20 mar. 2019.

OXFAM. País estagnado: um retrato das desigualdades brasileiras. Brasil, 2018. Disponível em: < https://www.oxfam.org.br/sites/default/files/arquivos/relatorio desigualdade 2018 pais est agnado digital.pdf $>$. Acesso em: 20 nov. 2019.

SINASE/LEVANTAMENTO. Levantamento anual do SINASE. 2016.

Disponível em: < https://www.direitosdacrianca.gov.br/noticias-2017/divulgado-levantamento-anual-do-sistema-nacional-de-atendimento-socioeducativo >. Acesso em: 23 nov. 2019.

TEJADAS, S. Atuação em Redes: uma estratégia desafiadora na defesa dos Direitos de Crianças e Adolescentes. Revista Digital da Capacitação de Candidatos a Conselheiro(a) Tutelar: Conselho Tutelar - Eleições 2007, mar. 2009, p. 45-51. Disponível em: <http://www.crianca.mppr.mp.br/arquivos/File/ conselhos tutelares/rd_capacitacao_conselheiro tutelar.pdf $>$. Acesso em: 22 out. 2019. 